PACS 44.10.+i, 85.60.Jb

\title{
Quasi-active thermal control in LED street lights
}

\author{
Y.V. Trofimov, S.I. Lishik, P.P. Pershukevich, V.I. Tsvirko \\ The Republican Scientific and Production Unitary Enterprise "Center of LED and Optoelectronic Technologies of \\ National Academy of Sciences of Belarus", \\ 22, Logoiski Trakt, Minsk BY-220090, The Republic of Belarus \\ Corresponding author phone: (+37517)-281-13-35; e-mail: sergey.lishik@gmail.com,www.ledcenter.by
}

\begin{abstract}
In this paper, the hollow heat sink has been studied. The physical and mathematical model of a hollow heat sink and CFD modeling are proposed for fitting the experimental results. It has been shown that the model of a hollow heat sink allows to calculate the velocity (and temperature) of the air flow coming out of the hollow heat sink, to determine its dependence on the angle of the dissipated thermal power, length, and degree of fin and cross-sectional area of the hollow heat sink. The influence of the geometry of the inlets/outlets on the heat removal was analyzed. It has been shown that the efficiency of the quasi-active system increases significantly in the presence of external wind through the so-called "effect of spray".
\end{abstract}

Keywords: LED street light, hollow heat sink, modeling, air flow, CFD.

Manuscript received 18.12.12; revised version received 24.01.13; accepted for publication 19.03.13; published online 25.06.13.

\section{Introduction}

One of the most important requirements to the development of lighting devices with high-power LEDs is to remove heat from the active region of LEDs. As a rule, most of LED street lights use open heat sink, which advantages are simplicity of their design, a wide range of the suppliers of aluminum profiles, etc. However, in actual exploitation, open heat sink accumulates dust, dirt, and atmospheric precipitation, which can reduce the effectiveness of the heat sink, and accelerate degradation of LEDs. To solve this problem, these lamps may require occasional cleaning, which is not economically profitable for organizations exploiting LED street lights. On the other hand, solar energy in the daytime is absorbed by fins because of multiple reflections from them, that also leads to heating the heat sink and breach of temperature storage conditions.

The hollow heat sinks with heat dissipating (finned) surface protected from contamination are the alternative to the open heat sink. As on certain conditions air draught appears in the hollow heat sink, these cooling systems can be classified as the quasiactive ones $[1,2]$. This paper deals with the hollow heat sinks researches.

\section{The hollow heat sink model}

The hollow heat sink, produced by the CLOET, NAS of Belarus, is used as the object of the research, and represents a solid extruded aluminum part.

Fig. 1 shows the calculated temperature distribution for open and hollow types of the heat sinks, other things for other conditions being equal: the design and material of the heat sink, heat power $P$ is $100 \mathrm{~W}$, the operation angle of the LED luminaire is $15^{\circ}$, the maximum ambient temperature $T_{0}=40{ }^{\circ} \mathrm{C}$.

Comparison of Figs $1 \mathrm{a}$ and $1 \mathrm{~b}$ shows that the temperature of the hollow heat sink is only $0.5^{\circ} \mathrm{C}$ higher than that of the open heat sink. This result is achieved due to (a) good thermal contact of cover and heatdissipating surface of the heat sink; (b) air draught occured in the hollow heat sink.

Let's consider a hollow heat sink with sizes $L \times W \times H$ (Fig. 2) mounted at an angle $\alpha$ to the horizontal plane. There are inlets/outlets air holes at the ends of the heat sink. As a result of the LEDs working out the total heat power $P$, the air inside the hollow heat sink gets hot and goes air draft that causes the air draught.

According to Bernoulli's equation: 

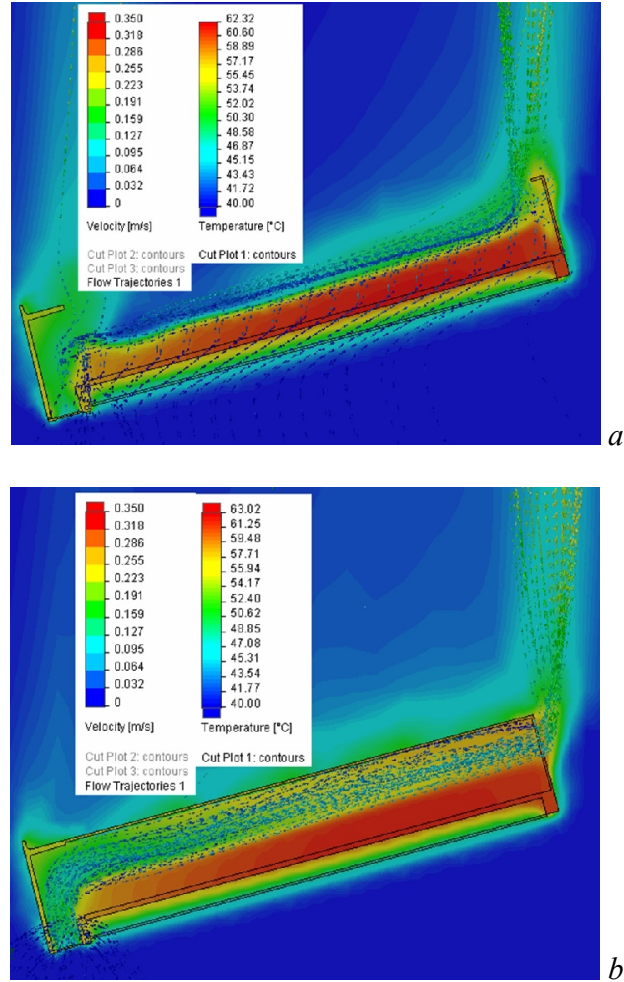

Fig. 1. The calculated temperature distributions for open (a) and hollow (b) types of the heat sink.

$p_{0}+\frac{\rho_{0} v_{0}^{2}}{2}=p+\frac{\rho v^{2}}{2}+\rho g h+\theta$,

where $p_{0}$ and $p, \rho_{0}$ and $\rho, v_{0}$ and $v$ are the pressure, density and velocity of air in the inlets/outlets air holes, respectively, $g$ is the gravity acceleration, $h$ - height of mounted heat $\operatorname{sink}(h=\sin \alpha), \theta-$ hydraulic loss pressure.

In the case of laminar air flow (Reynolds number $\operatorname{Re}<2300)$ :

$\theta=\frac{32 \eta L v_{i n}}{D^{2}}+\xi_{1} \frac{\rho_{0} v_{0}^{2}}{2}+\xi_{2} \frac{\rho v^{2}}{2}$,

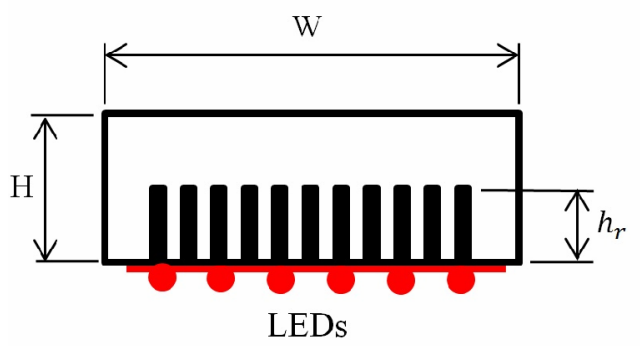

Fig. 2. Model of the hollow heat sink. where $\eta$ is the viscosity of air, $v_{i n}$ - average speed of air in the heat sink, $D-$ hydraulic diameter ( $D=2 W H /\left(h_{r} n+W+H\right)$, where $h_{r}$ and $n$ are the height and number of fins, respectively), $\xi_{1,2}-$ local loss coefficients for inlets/outlets air holes.

It should be noted that according to Fig. 1a the air velocity in inlets/outlets air holes correlates as $1: 15 \ldots 1: 20$, i.e. $v_{0}<<v$. Therefore, the second components in the left side of Eq. (1) and in the righthand side of Eq. (2) can be neglected, and the average velocity of the air inside the heat sink set is equal to $v_{\text {in }}=v / 2$.

The pressure difference between the inlet and outlet of the hollow heat sink is equal to the weight of the column of air $p_{0}-p=\rho_{0} g h$, meanwhile the density of air depends on its temperature $\rho=\rho_{0} T_{0} / T$, where $T_{0}, T$ are air temperature at the inlets/outlets of the hollow heat sink respectively. Taking the above mentioned into consideration, we will get the following expressions from (1):

$$
\begin{aligned}
& \left(1+\xi_{2}\right) \frac{\rho v^{2}}{2} \approx \rho g h\left(\frac{\rho_{0}}{\rho}-\frac{16 \eta L v}{D^{2} \rho g h}-1\right)= \\
& =\rho g h\left(\frac{T_{0}}{T}-\frac{16 \eta L v}{D^{2} \rho_{0} g h} \frac{T_{0}}{T}-1\right) .
\end{aligned}
$$

The air temperature $T$ inside the heat sink can be determined using:

$$
\begin{aligned}
& \Delta T=T-T_{0}=\frac{Q}{V C \rho}=\frac{P t}{V C \rho}=\frac{P}{V C \rho} \frac{L}{\langle v\rangle}=\frac{2 P L R T}{V C p_{0} v}, \\
& T=T_{0} \frac{V C p_{0} v}{V C p_{0} v-2 P L R} .
\end{aligned}
$$

where $Q$ is the acquired energy, $V$ - volume of hollow heat sink, $C$ - heat capacity of air, $t$ - time of air heating, i.e. time of heat sink air passage, $R$ - universal gas constant.

After substituting (5) into (3) and math transformations, we obtain the cubic equation:

$v^{3}+a v^{2}+c \approx 0$,

\section{(C) 2013, V. Lashkaryov Institute of Semiconductor Physics, National Academy of Sciences of Ukraine}


where

$$
\begin{aligned}
& a=\frac{2\left(16 \eta V C p_{0}-\left(1+\xi_{2}\right) D^{2} \rho_{0} P R\right)}{\left(1+\xi_{2}\right) D^{2} \rho_{0} S C p_{0}}, \\
& c=-\frac{4 g P R L \sin \alpha}{\left(1+\xi_{2}\right) S C p_{0}} .
\end{aligned}
$$

Using the trigonometric formula Wyeth, one can find the real root:

$$
v=\frac{2 a}{3} \operatorname{ch}\left(\frac{1}{3} \operatorname{Arch}\left|\frac{2 a^{3}+27 c}{2 \sqrt{a^{3}}}\right|\right) \text {. }
$$

\section{Comparison of the model with CFD and experimental results}

The developed model can describe the results of CFD modeling in the SolidWorks Flow Simulation (Fig. 3)

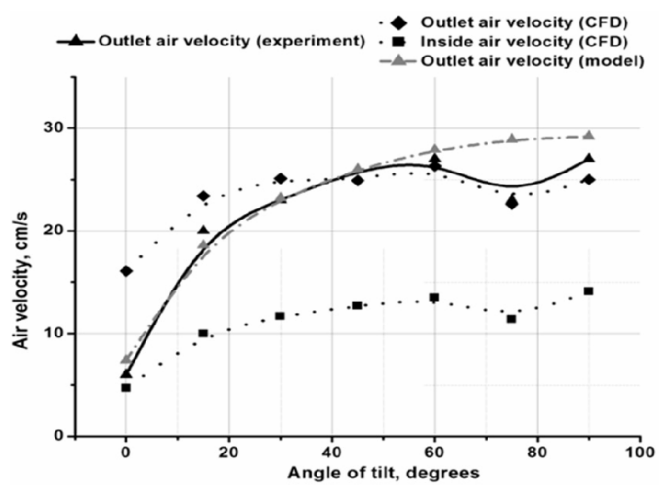

$a$
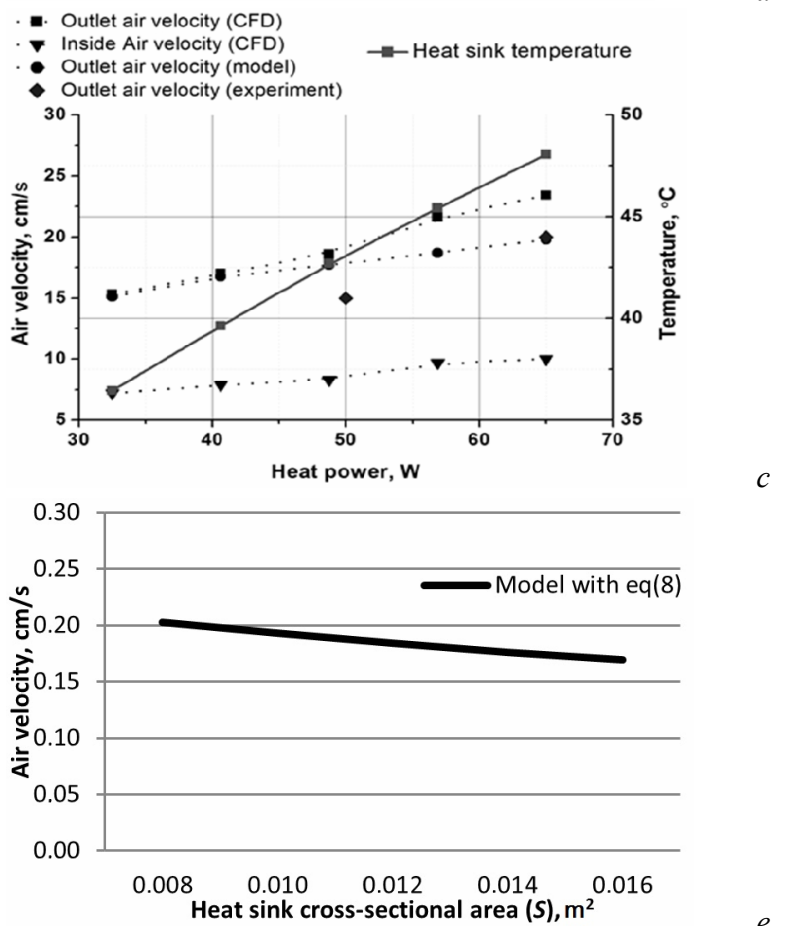

and the experiments (Fig. 4) wherever it is possible (at $\xi_{2}=6.0$ ). Testo $435-2$ is used for measuring the velocity and temperature of the exhausted air, meanwhile the thermal FLIR A325 is for thermal measurements.

Fig. 3a shows that the optimal angle of LED luminaire is above or equal to $15^{\circ}$, meanwhile the velocity of air flow output is about $70 \%$ of its maximum. Significant divergence of the model from the experiment and CFD results is observed at the angles of setting higher than $60^{\circ}$, which can be explained by the transition from laminar to turbulent air flow. Along with the growth of the rate of air flow, its temperature is increased and the temperature of the luminaire is reduced (Fig. 3b).

The air flow velocity inside the heat sink and its temperature increase linearly with growth of power dissipation (Fig. 3c). The observed deviation from linearity is caused by the temperature gradient of the air inside and outside the heat sink.
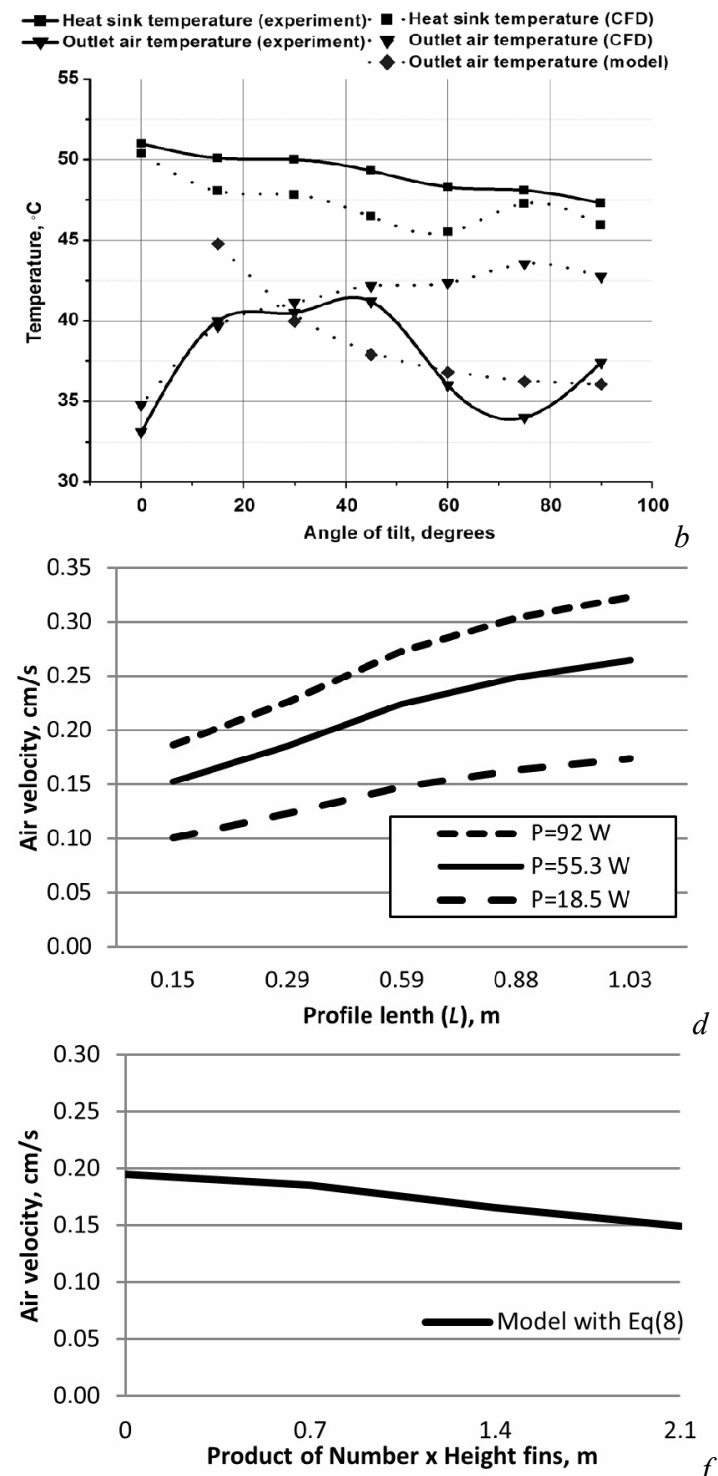

Fig. 3. Dependence of the air velocity (a) and temperature (b) on the operation angle, air velocity on heat capacity (c), length (d), cross-section area (e) and number of fins (f) of a hollow heat sink, obtained from (5), (7) and by numerical modeling (CFD).

\section{(C) 2013, V. Lashkaryov Institute of Semiconductor Physics, National Academy of Sciences of Ukraine}



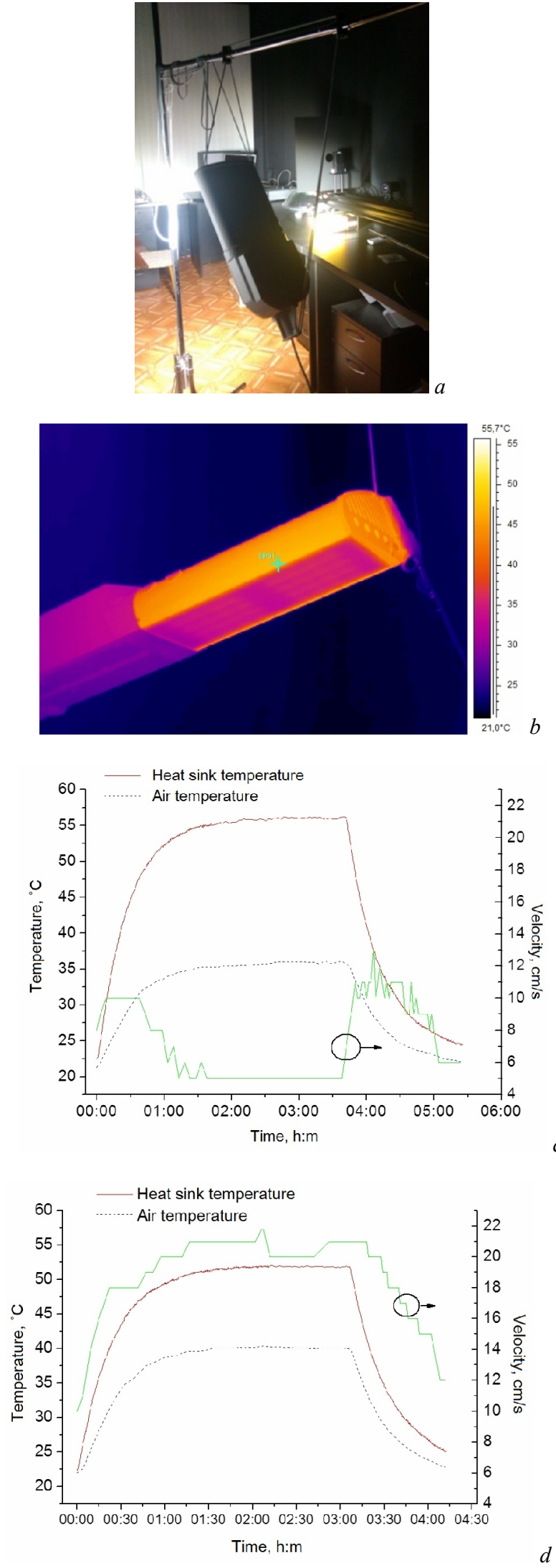

Fig. 4. The experimental setup (a), the thermogram of the lamp after $3 \mathrm{~h}(\mathrm{~b})$ and behavior of the air flow rate and temperature at $\alpha=0^{\circ}$ (c), and $\alpha=15^{\circ}$ (d).
The air flow velocity is increasing with the growth of the hollow heat sink (Fig. 3d), however, the velocity growth rate of air-out flow is slowing down for large values of $L$.

The air-out flow velocity increases, while crosssection area of the hollow heat sink is decreased (Fig. 3d). This effect is caused by the heated air contraction, which results in increasing the temperature and air density difference inside and outside of the heat sink. Also, it leads to increase of the intensity of draught. In addition, when decreasing the cross-section of the heat sink, its hydraulic diameter $D$ decreases. The higher is $D$ value (i.e. the less is the product of $h_{r} n$ ), the lower is the friction of the air on the wall of the heat sink and the higher is the air velocity. On the other hand, when there is an insufficient area of the heat-dissipating surface, the temperature of the luminaire and LED temperature are increased significantly, which results in their degradation. Thus, the parameters $D$ and $h_{r} n$ should be selected as based on the minimization of the heat sink temperature.

According to the results of the CFD modeling, the maximum impact on the efficiency of the hollow heat sink has the ratio of input/output areas of air holes $\mathrm{Sin} /$ Sout (Fig. 5). It is recommended to use heat sink with maximally open input and output air holes (Embodiments №1, Fig. 5). The temperature of the heat sink reduces to $60{ }^{\circ} \mathrm{C}$ due to increasing the air flow inside the heat sink to $v_{\text {in }} \approx \frac{v}{2}$.

Experimental investigation of behavior of heating the LED street light (Fig. 4) shows that at the angle $15^{\circ}$ output air velocity is $22 \mathrm{~cm} / \mathrm{s}$, the maximum heat sink temperature is reduced from $56{ }^{\circ} \mathrm{C}$ to $52{ }^{\circ} \mathrm{C}$, and the temperature of the exhausted air is increased from $36{ }^{\circ} \mathrm{C}$ to $40{ }^{\circ} \mathrm{C}$. The emergence of air draught immediately after the switching on/off a horizontal LED street light is caused by the heating/cooling the air inside the heat sink, which results in the coming/outgoing air flows, trying to align the density of the air inside and outside of the heat sink.

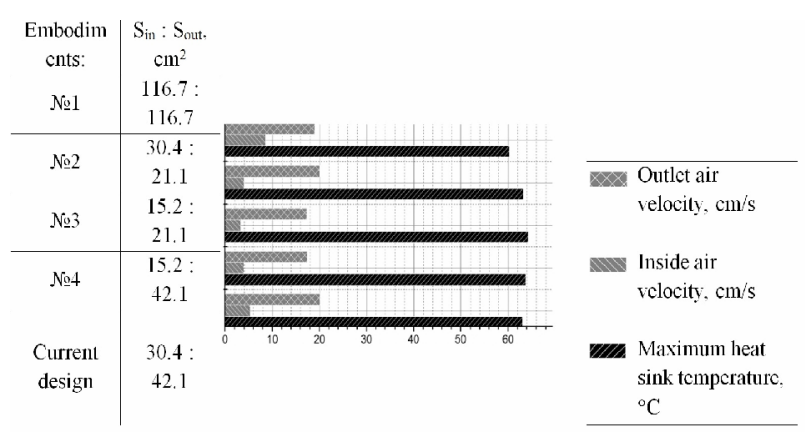

Fig. 5. Comparison of different options of LED lamps (at $P=100 \mathrm{~W}, \alpha=15^{\circ}$. 
It should be noted that in actual efficiency of quasiactive cooling system based on hollow heat sink significantly is much higher due to the effect of spray. Indeed, if the outlet of the heat sink is blown by the wind at a speed of $v_{0}$ relatively to the air inlet holes, then $p_{0}-p=\frac{\rho v_{0}^{2}}{2}$, while the expression (1) neglecting losses $(\theta=0)$ transforms to the following one:

$$
\frac{\rho v^{2}}{2} \approx \rho\left(\frac{v_{0}^{2}}{2}-g h\right) \text {. }
$$

From (8), we can conclude that the air draught appears at $v_{0}>\sqrt{2 g h}$, i.e. even a weak wind $\left(v_{0} \approx 2 \mathrm{~m} / \mathrm{s}\right.$ ) for heat sink meets this condition. At the LED street light installation at the angle $\alpha=15^{\circ}$ and speed, for example, $v_{0}=3 \mathrm{~m} / \mathrm{s}$, the air draught is $2.7 \mathrm{~m} / \mathrm{s}$, and if $v_{0}=10 \mathrm{~m} / \mathrm{s}$ it is increased to $9.9 \mathrm{~m} / \mathrm{s}$. Obviously, with such air velocity through the hollow heat sink, the temperature is reduced significantly.

\section{Conclusions}

The physical-and-mathematical model of a hollow heat sink that allows to calculate the velocity and temperature of coming/outgoing air flows in the hollow heat sink, to determine its dependence on the operation angle, the dissipated thermal power, length, cross-section area and degree finning of the hollow heat sink has been developed. The model agrees well with the experimental data and computer modeling. The influence of the geometry of inlets/outlets on the heat removal has been analyzed. It has been shown that the efficiency of the quasi-active system increases significantly in the presence of external wind through the effect of spray.

Thus, the quasi-active system based on hollow heat sinks is promising, long-lasting, reliable, and able to provide thermal control of LEDs.

References

1. O. Stukalov, "Triumph" of the LED Street Lights // Solid-state lighting, 4(18), p. 68-71 (2012), in Russian.

2. M. Goncharov, Air movement - the life of the lamp // Solid-state lighting, 5(19), p. 64-65 (2012), in Russian. 